Article

\title{
A Study of Transport Behaviour of Academic Communities
}

\author{
Aleksandra Romanowska *D, Romanika Okraszewska $\mathbb{D}^{\mathbb{D}}$ and Kazimierz Jamroz \\ Faculty of Civil and Environmental Engineering, Gdansk University of Technology, 80-233 Gdańsk, Poland \\ * Correspondence: aleksandra.romanowska@pg.edu.pl; Tel.: +48-58-347-17-97
}

Received: 16 May 2019; Accepted: 24 June 2019; Published: 27 June 2019

check for updates

\begin{abstract}
An important challenge to achieving sustainable university campuses is ensuring that the academic community makes sustainable transport choices. The objective of this study was to investigate the daily commuting patterns, identify the potential for change, and determine the factors and criteria affecting the transport decisions of academic communities of two universities located in Gdansk, Poland. This paper summarizes the results of trip generation measurements and a comprehensive online survey of 3678 respondents, including the universities' staff and students. Analysis of survey results revealed clear differences between students and university staff in terms of travel patterns and factors that influence their choices. Staff usually $(57 \%)$ choose the car for daily commutes with students opting for public transport (59\%). The choice of travel mode in particular groups is determined mostly by car availability, trip origin location, and accessibility. The choices also depend on transport user individual requirements such as trip quality, costs, or ecology. With approximately 1400 trips daily per 1000 students, the universities are large traffic generators. Thus, how the staff and students behave determines the effect the universities have on the urban transport system. Understanding the behaviour can help to estimate whether it can be changed and how.
\end{abstract}

Keywords: university campus; transport behaviour; sustainable university; sustainable transport

\section{Introduction}

Dependence on car use has adverse environmental, social, and economic consequences. The major effects of transport on the environment include pollution, global warming, noise, vibration, resource use, and waste disposal [1,2]. The major effects of transport on society include social exclusion and inequity due to inadequate mobility and lack of access to opportunities and social networks [3], exposure to stress, and the health effects of heavy traffic. Each of the undesirable effects has its economic dimension and constitutes the external costs of transport.

In combination with estimates that by 2050 cities will have attracted $70 \%$ of the global population, the problem of urban mobility has advanced to the top of the political agendas worldwide [4]. As well as new technologies, infrastructure and systems, the new mobility culture requires solutions for managing the mobility of urban communities to change their transport patterns into more sustainable ones [5-7].

Social norms, the informal rules that govern behaviour in groups and societies, have been extensively studied in the social sciences. The approach to conception of norms as presented by Deutscher [8] is crucial in explaining social action, and considers social identity as a key motivating factor. The entities that are best positioned for fostering a new urban mobility culture must be able to carry the message to large groups of society or large groups of people, including in particular the authorities but also employers, religious groups, the media, and institutions of education. 
Universities have a significant role to play in the process of changing from current worldwide patterns of unsustainability to sustainability in general [9]. The special role of universities results from their educational function, the range of spatial and social impact. Many universities have paid a great deal of attention to sustainability as evidenced by numerous conferences and signed declarations, initiated in 1990 by the Talloires Declaration [10]. If they want to promote sustainable development, universities must tackle transport because students, staff, and visitors moving to and from the campus are one of the critical factors of how it impacts the environment and society [11]. Because their influence does not stop at the academic community level, universities have an important role to play in promoting population-wide sustainable transport behaviour. Students are a social group with a high willingness to adopt new ideas and make lifestyle changes. The knowledge, values and attitudes gained in the educational process are transferred to the wider public by university graduates taking up various professions. This helps to raise awareness and forms urban mobility opinions. However, the transport behaviour of graduates is also influenced by other factors, mostly economic, when they move into work. Social factors related to the organizational culture of the new workplace also play a role. These factors may affect everyday transport choices.

Universities are often referred to as "cities within a city", a consequence of the area they occupy and the size of their communities [12,13]. The study of Okraszewska et al. [14] has shown that academic communities represent a big portion when compared to the overall city population ( $9 \%$ to $22 \%$ in Polish cities). As a consequence, how they behave using transport affects the immediate neighbourhood and the city in general [15-18]. University commutes affect the areas around them as a result of the number of trips and how they are made. The impact is particularly noticeable when the university is located within a city [15]. The traffic generated by universities may add up to a sizeable proportion of all urban trips $[13,18]$.

While the sustainable development paradigm is a critical driver of university development, many of Poland's, Europe's and the world's universities pay too little attention to transport [19]. Although many campuses are designed to encourage walking, academic communities still give in to the omnipresent culture of motorization. Because car trips are usually a popular commuting mode, there is an expectation and pressure from university communities on the authorities to provide parking space and new road infrastructure [20].

Before informed, individual or integrated steps are taken to promote sustainable transport patterns at universities, it is important to understand the current transport behaviour of their academic communities. The objective of this study was to investigate the daily commuting patterns, identify the potential for change and determine the factors and criteria affecting the transport decisions of two largest academic communities in northern Poland - the University of Gdansk (UG) and the Gdansk University of Technology (GUT). The research was based on online surveys and trip generation measurements conducted in order to understand the academic communities for how they travel, how many trips they make, what daily transport choices they make and how willing they would be to swap the car for alternative modes of transport. Understanding the behaviour and why it happens can help to identify the potential for change in university travel patterns. Furthermore, understanding the scale of the university as a traffic generator, we can identify how possible changes in the behaviour of academic communities can influence the number of car trips and thus reduce the negative influence on the urban transport system. This may be particularly important in cities such as Gdańsk, where the share of the academic community is $15 \%$ compared to the total population. The article is a continuation of and complement to previous work on transport patterns, behaviour and preferences of academic communities, and the effects universities have on cities' transport systems [14,18,21].

The next section provides a brief review of the literature and research on the transport behaviour of academic communities (Section 2). This review is followed by a presentation of the research methodology, including surveys, traffic measurements and data analysis (Section 3). We then present the results of the analyses (Section 4), discuss the main results and findings of the research (Section 5), ending with the main conclusions including future research directions (Section 6). 


\section{Background}

A number of studies can be found that deal with different aspects of the travel patterns of university or college students. They fall into three main groups:

- Theoretical considerations about the definition of sustainable university, the challenges faced by university authorities as they pursue a vision of a sustainable university $[9,12,22]$, or the methods for managing community transport behaviour [11,23];

- Focussing on specific issues or factors affecting transport choices [24,25] or assessing mobility management efforts [15];

- Results of research to diagnose the current situation, provide knowledge on academic community transport behaviour and transport preferences for a selected university, campus, or groups of university facilities [26].

Surveys are the prevailing method for studying transport preferences and transport choices [27]. Some of the studies use traffic counts, automatic counts or GPS-based applications [28]. Studies address entire communities [26,29], sometimes staff only, and mostly students who are the largest group within a university community [13]. In case of traffic counts, studies sporadically cover traffic as a whole with all modes included and are mostly confined to pedestrians and/or cyclists [13]. In this study a comprehensive approach was applied - the study covers the entire university community, focuses on all transport modes and is based on a combination of surveys and traffic counts.

The results of the research known from the literature create a set of diverse transport behaviours displayed by different academic communities [29]. As well as having different transport patterns, universities also differ in terms of their communities [30]. By applying the criterion of function, age, car ownership and other variables, sub-groups can be identified, each with different transport patterns. Transport choices are often influenced by factors that are part of one of the groups below [24]:

- Personal characteristics: Gender [13], age, status, income, car availability [31], driving license, employment [13],

- Psychological factors such as habit, attitude, concerns over health and the environment, familiarity with alternative modes to driving and an unconscious attachment to car usage [32],

- Factors that characterise a transport mode (i.e., comfort, directness, costs, ecology) [33],

- Trip characteristics such as time of travel, trip purpose, trip distance, trip origin and destination [34],

- The built environment of trip origin or destination, including pedestrian, cycling and public transport infrastructure, street networks and car parks [13,29,31,35],

- A presence of Travel Demand Management (TDM) measures such as parking cost or restriction information campaigns against car usage and transit pass subsidy [15].

While many studies focus on a specific issue or related factors affecting transport choices, our study provides a ranking of transport mode selection criteria depending on objective independent variables related to personal characteristics and subjective variables related to psychological conditions, trip characteristic, and assessment of the built environment.

The literature includes studies on the academic communities of universities in the US $[13,22,36]$, Canada [31], Europe [14,15,18,21,29,31,37,38] and Asia [12,39]. With different levels of socio-economic and spatial development and motorization, European, American, and Asian countries differ significantly, a feature that can be seen not only in the size of the university but also in the behaviour of the community [40]. University structure (compact campus or many locations) or campus locations may differ as well (urban, sub-urban, or rural) [36]. Campus location has an important effect on community transport behaviour [31,37]. Rural and sub-urban campuses are normally more automobile-dependent than urban ones [36]. A significant impact on community transport choices is the distance of the place of residence from the university [41].

Thus, how the trips are made can result from many factors. Table 1 shows a few examples of universities of a similar community size and how trips to and from these universities are made. It can 
be noticed, that modal split differs significantly in each case, even if universities with similar locations are compared. This example shows that comparisons between universities should be made carefully and many factors should be taken into account, such as local conditions, size of the community, university structure (compact campus or many buildings scattered across the city), location (urban, sub-urban, rural), and accessibility by public transport, which can largely influence transport behaviour of academic communities.

Table 1. Modal split at selected universities featuring different locations [36,42].

\begin{tabular}{|c|c|c|c|c|c|c|c|c|}
\hline \multirow{2}{*}{ Country } & \multirow{2}{*}{ City } & \multirow{2}{*}{ University } & \multirow{2}{*}{ Community } & \multirow{2}{*}{ Location } & \multicolumn{4}{|c|}{ Modal Split } \\
\hline & & & & & Car & PT * & Bike & Walk \\
\hline Canada & Montreal & $\begin{array}{c}\text { McGill } \\
\text { University }\end{array}$ & 40,000 & urban & $16 \%$ & $55 \%$ & \multicolumn{2}{|c|}{$29 \%$} \\
\hline USA & New York & $\begin{array}{c}\text { Cornell } \\
\text { University }\end{array}$ & 31,800 & rural & $40 \%$ & $9 \%$ & $6 \%$ & $45 \%$ \\
\hline USA & California & $\begin{array}{c}\text { US Santa } \\
\text { Barbara }\end{array}$ & 29,100 & sub-urban & $51 \%$ & $4 \%$ & $37 \%$ & $8 \%$ \\
\hline USA & Washington & UW Seattle & 49,200 & urban & $38 \%$ & $31 \%$ & $5 \%$ & $25 \%$ \\
\hline
\end{tabular}

This study provides knowledge on academic community transport behaviour and transport preferences in the context of Polish universities. The majority of Poland's public universities are located in major cities such as Warsaw, Gdansk, or Cracow. The largest universities are located within the city structure and their campuses are usually close to the city centre or in strategic locations with good public transport availability, and connectivity. Thus, while the observations form GUT or UG can be compared to other Polish universities, other local conditions that may affect transport behaviour must also be considered. Similarly, the research results presented in this article can also be referred to European universities with an urban location on compact campuses and very good links to public transport.

\section{Methodology}

\subsection{Study Sites}

Poland's higher education services are largely found in major cities such as Warsaw, Cracow, or Gdansk. A port city, Gdansk is Poland's sixth most populated city (more than 460,000) and seventh for size (more than $260 \mathrm{~km}^{2}$ ). Car ownership is 550 cars per 1000 population. With its unusual alignment, Gdansk features a linear transport system. The city's main road and rail axis is populated with shops, services, and education facilities, including Gdansk's biggest universities. Because it is linear, the system cumulates trips along the main transport axis and on its access roads. As a result, Gdansk, just as the majority of big cities is clogged by congestion, an effect of many trips and the popularity of the car as a mode of transport. On a daily basis, Gdansk can record about 870,000 trips [43], of which $39 \%$ are by car, $38 \%$ by public transport, $22 \%$ walking, and $2 \%$ cycling. Considering the size of Gdansk's academic community (15\% in relation to Gdansk's population), a high percentage of trips will be generated by university students and staff. This becomes quite clear when we compare road traffic and public transport traffic during the academic year and when schools are closed for holidays.

The Gdansk University of Technology (GUT) and the University of Gdansk (UG) are the biggest universities in north Poland. Both have urban locations and compact campuses with just a few of their facilities located outside the main locations. UG is situated in Oliwa, a dynamically developing district and home to academic, office, commercial, and residential uses. UG has more than 30,000 students with nearly 3200 staff. A clear majority studies or works in the university's main campus called Oliva Campus. GUT is situated in Wrzeszcz, a district which for years has been Gdansk's main commercial and service hub. GUT has nearly 24,000 students and more than 2700 staff. Nearly all of 
the university's buildings are located on the main campus. UG and GUT combined represent $85 \%$ of Gdansk's academic community. Both universities have similar characteristics such as their location along the city's main transport axis (Figures 1 and 2), access to public transport, transport services and how both universities operate.

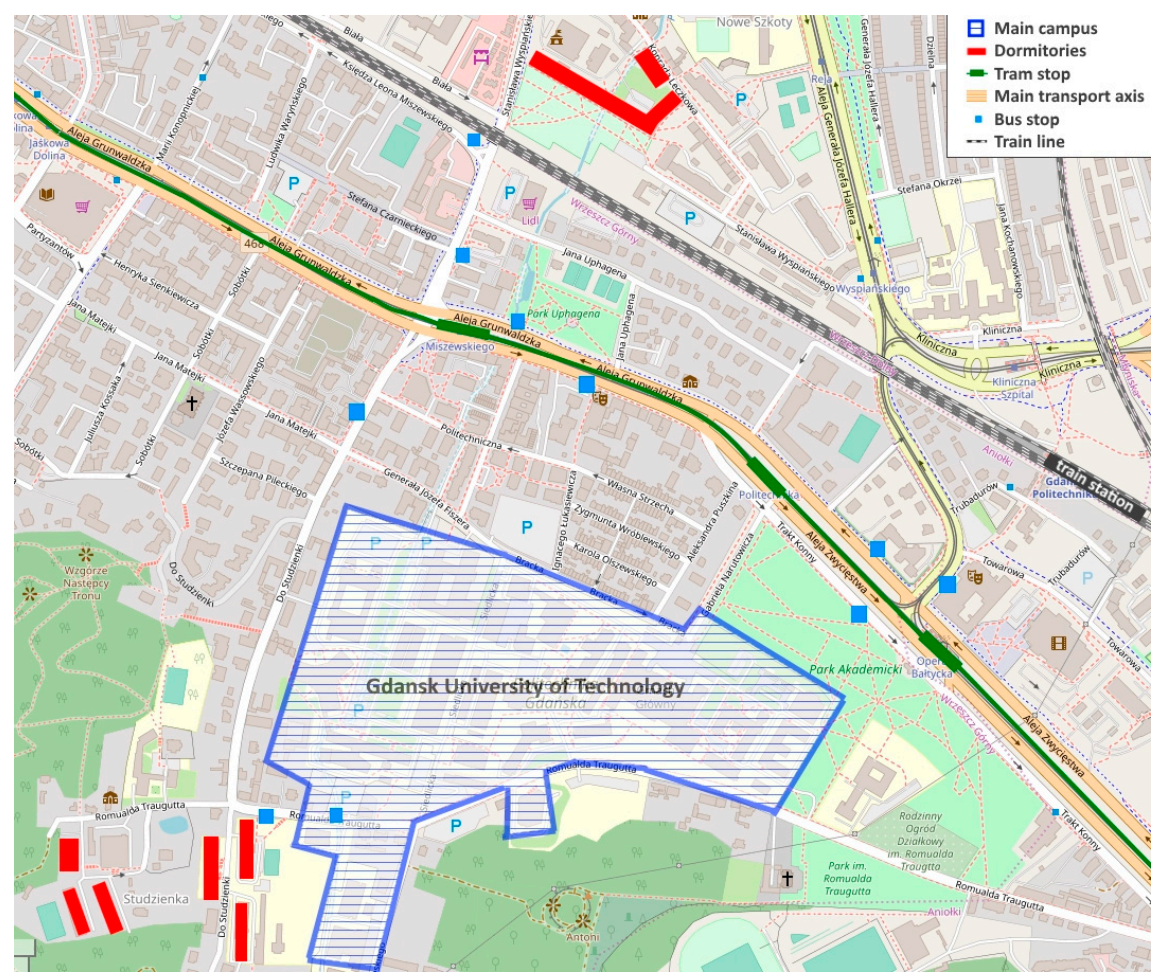

Figure 1. Location of the Gdansk University of Technology (source: OpenStreetMap).

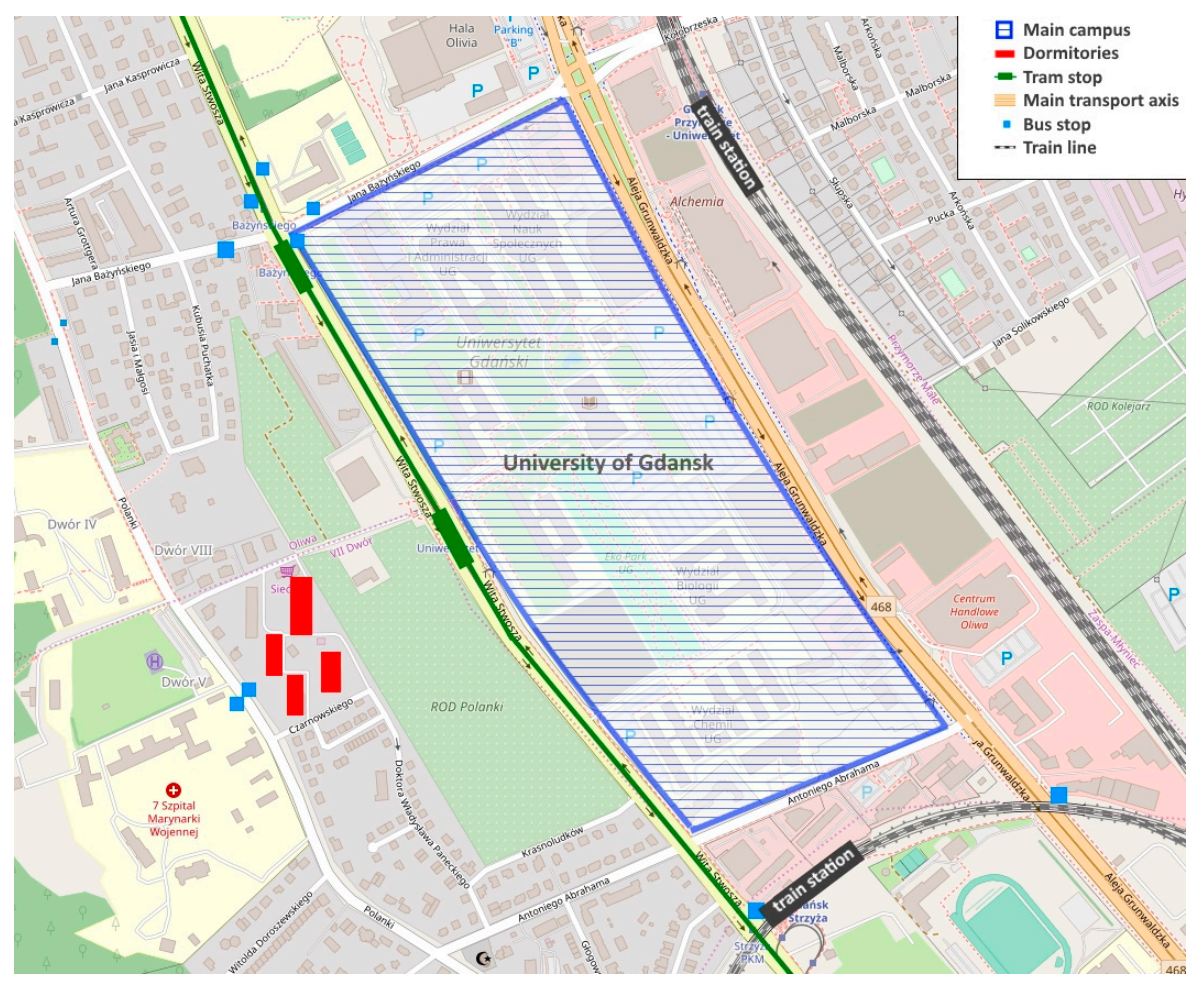

Figure 2. Location of the main campus of the University of Gdansk (source: OpenStreetMap). 
The transport services of both universities comprise internal services within the campuses and external services linked to the adjoining streets, public transport stops, car parks, and university buildings outside the campuses. Because both universities are located on the city's main transport axis, they have excellent links to Gdansk's transport network and to public transport (access to the bus, tram and train network), cycling and pedestrian infrastructure. UG's Oliwa campus has about 1500 parking spaces for staff and students. With a capacity of about 700 parking spaces, GUT provides parking for its staff only. Because parking is limited in both universities, many people park illegally on the campus or outside it-in designated parking places, in on-street parking, on semi-legal and legal sites. Some park in nearby residential streets, causing a nuisance for the residents.

\subsection{Surveys}

To support our analyses, GUT and UG academic communities were asked to take part in a survey. The online questionnaire was distributed by an internal mail system to e-mail addresses of all staff and students. Participation was voluntary and anonymous.

The purpose of the survey was to understand the structure of academic community for its transport preferences, daily transport choices and willingness to reduce car use and choose alternative transport modes instead (Table 2).

Table 2. Questionnaire design.

\begin{tabular}{|c|c|c|}
\hline \multicolumn{2}{|c|}{ Questionnaire Outline } & Information Gained \\
\hline General information & $\begin{array}{c}\text { University, Gender, Age, Status } \\
\text { (student/employee), Unit, Function, Position } \\
\text { (employees), Additional duties/employment } \\
\text { (students), Place and type of residence } \\
\text { (students) }\end{array}$ & Profile of respondent \\
\hline $\begin{array}{l}\text { Usual travel characteristics to and } \\
\text { from university }\end{array}$ & $\begin{array}{l}\text { Origin of travel, Car availability (owning or } \\
\text { shared use within the family), Degree of the } \\
\text { usage of particular transport options, Average } \\
\text { travel time, Time of travel to/from university } \\
\text { on particular days, Frequency of travel }\end{array}$ & $\begin{array}{l}\text { Usual transport behaviour and } \\
\text { travel patterns in travelling } \\
\text { between the place of residence and } \\
\text { the university }\end{array}$ \\
\hline $\begin{array}{l}\text { Travel characteristics to and from } \\
\text { university on selected day }\end{array}$ & $\begin{array}{l}\text { Selected transport mode, Destination of travel } \\
\text { (building no.), Entry and exit used }\end{array}$ & \multirow{5}{*}{$\begin{array}{l}\text { Travel characteristics to and from } \\
\text { university with reference to a } \\
\text { representative day (last Tuesday at } \\
\text { the university) }\end{array}$} \\
\hline - Car & $\begin{array}{l}\text { Car occupancy, Access to internal parking } \\
\text { (parking card), Selected parking place }\end{array}$ & \\
\hline - Public transport & $\begin{array}{l}\text { Public stops used, Multimodality of travel, } \\
\text { Number of transfers, Using P\&R }\end{array}$ & \\
\hline - Bicycle & $\begin{array}{l}\text { Bike parking, Multimodality of travel, Using } \\
\text { B\&R }\end{array}$ & \\
\hline - Walk & - & \\
\hline $\begin{array}{l}\text { Determinants of transport mode } \\
\text { choice }\end{array}$ & $\begin{array}{l}\text { Factors determining the choice of transport } \\
\text { mode }\end{array}$ & $\begin{array}{c}\text { Importance of particular factors in } \\
\text { reference to particular transport } \\
\text { modes }\end{array}$ \\
\hline Tendency for changes & $\begin{array}{l}\text { Tendency and possibility of changing } \\
\text { transport behaviour, Attitude to sustainable } \\
\text { alternatives: carpooling, bike sharing }\end{array}$ & $\begin{array}{l}\text { Attitude to: change of transport } \\
\text { mode (car users only), use of } \\
\text { alternatives }\end{array}$ \\
\hline
\end{tabular}

The survey covered a total of 3378 people, staff and students of both universities. Depending on the surveyed group, the response rate ranged from $3 \%$ to $29 \%$ (Table 3). In order to verify if the number of respondents meets the requirements of the minimum sample size, the formula given by Smith [44] was used (Formula (1)). Having a big enough sample is important if we want to draw inferences about the entire university community based on the group surveyed.

$$
N_{\min }=\frac{p(1-p)}{\frac{d^{2}}{Z^{2}}+\frac{p(1-p)}{N}}
$$


where: $N_{\min }$ is a minimum sample size, $N$ is a size of the target population, $p$ is the unknown response distribution $(p=50 \%), Z$ is the normal variate for $95 \%$ confidence $(Z=1.96)$ and $d$ is an absolute accuracy level ( $d=5 \%$ was applied).

Based on the calculated minimum sample size (Table 3) it can be confirmed that in the case of each surveyed group the number of respondents meets the requirements of a minimum sample size.

Table 3. Surveyed groups, their population, and sample size.

\begin{tabular}{|c|c|c|c|c|c|c|c|}
\hline \multicolumn{2}{|c|}{ Surveyed Group } & $\begin{array}{c}\text { Population } \\
\text { Size }\end{array}$ & $\begin{array}{l}\text { Start of the } \\
\text { Survey }\end{array}$ & $\begin{array}{l}\text { Survey } \\
\text { Period }\end{array}$ & $\begin{array}{c}\text { Number of } \\
\text { Respondents }\end{array}$ & $\begin{array}{c}\text { Response } \\
\text { Rate }\end{array}$ & $\begin{array}{c}\text { Minimum } \\
\text { Sample Size }\end{array}$ \\
\hline \multirow{2}{*}{ GUT } & employees & 2747 & 05.2016 & 2 weeks & 803 & $29.2 \%$ & 338 \\
\hline & students & 23,793 & 05.2017 & 3 weeks & 1394 & $5.9 \%$ & 379 \\
\hline \multirow{4}{*}{ UG } & employees & 3169 & \multirow[b]{2}{*}{05.2018} & \multirow[b]{2}{*}{3 weeks } & 489 & $15.1 \%$ & 343 \\
\hline & $\begin{array}{c}\text { main } \\
\text { campus }\end{array}$ & $\sim 2800$ & & & 386 & $13.8 \%$ & 338 \\
\hline & students & 30,595 & \multirow[b]{2}{*}{05.2018} & \multirow[b]{2}{*}{3 weeks } & 992 & $3.2 \%$ & 380 \\
\hline & $\begin{array}{c}\text { main } \\
\text { campus }\end{array}$ & $\sim 23,000$ & & & 666 & $2.9 \%$ & 378 \\
\hline
\end{tabular}

The questionnaire was conducted in the spring, from May to June. The reason why this period was selected was the good weather (encouraging active forms of mobility) and regular study periods with no days off or university events.

\subsection{Statistical Analysis}

The sample's representativeness was tested by comparing it to the population for its share in the particular university units and functions. The analyses showed that the respondents represented a similar proportion of overall university functions and population. In both cases, staff functions were found to be significantly $(\sim 10 \%)$ underrepresented in the category of service employees (cleaning, maintenance service, etc.) who range from $14-17 \%$ of university staff. This is probably because service staff may have limited access to a computer or university e-mail. Considering the differences in the structure of the sample and population, a rim (Random Iterative Method) weighting algorithm was applied to ensure a representative sample. The weighting methods are commonly used in quantitative market research in order to achieve the representative sample in relation to the known target population characteristics [45]. In the case of rim algorithm, the weighting is done against several criteria. In the study three criteria were used: University, status and function.

It was important to relate the respondents' declared transport behaviour and preferences to the location and attractiveness of the sources of their university commutes. An indicator was proposed to express public transport (PT) accessibility $A_{P T_{i}}$ from trip origin to its destination (Formula (2)). Public transport accessibility can be defined as the degree of ease with which it is possible to get from a given city district, $i$, to a given university with the use of existing public transport infrastructure and services. The indicator takes into account the public transport infrastructure in a given district (as part of the district's built environment), the available public transport connections between the district and a given university and the average time needed to travel between the district and the university using the available public transport services. The indicator can be from 0 to 1 . The higher the rate, the better the accessibility and convenience of public transport commutes. The indicator only applies to people commuting within Gdansk (when the trip origin is located in Gdansk).

$$
A_{P T_{i}}=w_{1} \times A_{T_{i}}+w_{2} \times A_{R_{i}}+w_{3} \times T_{P T_{i, n}}+w_{4} \times D_{P T_{i}}
$$

where: $A_{T_{i}}$ and $A_{R_{i}}$ denote whether a tram and train service connection is available from the district $i$ (0-absent, 1-present), $D_{P T_{i}}$ denotes whether PT services are available for direct travel from the district, $i$, to the university (1-ability to use a direct service, 0 -having to transfer), $T_{P T_{i, n}}$ is a normalised travel 
time by PT, calculated using Formula (3), $w_{1}, w_{2}, w_{3}, w_{4}$ are weights of variable significance determined using an expert method and all adding up to 1.

$$
T_{P T_{i, n}}=1-\frac{T_{P T_{i}}}{T_{P T_{\max }}}
$$

where: $T_{P T i}$ is average time to travel by PT from the district $i$ to the given university and $T_{P T_{\max }}$ is average time to travel by PT from the furthest district to the given university.

A similar indicator $A_{W_{i, n}}$ was proposed to express on a scale of $0-1$ the possibility of walking from trip origin (district $i$ ) to destination (the university).

$$
A_{W_{i, n}}=1-\frac{T_{W_{i}}}{T_{W_{\max }}}
$$

where: $T_{W i}$ is average walking time from the district $i$ to the given university and $T_{W_{\max }}$ is average walking time from the furthest district to the given university.

The accessibility analysis showed that accessibility by PT is the highest for mixed land use districts and districts situated along Gdansk's main transport axis. Accessibility was the lowest for districts further away from the main transport axis which are largely residential in character. Walking accessibility is high in university districts or those directly adjacent to them.

Modes of transport were considered in four groups: the car, public transport, cycling, walking. Next, cross-analyses were conducted by combining a selected transport mode with respondent characteristics, location of trip origin/destination and others. This helped to identify academic community transport patterns and the factors that influence a respondent's choice of transport mode.

Transport choice factors were identified using the chi ${ }^{2}$ test of independence, followed with a strength statistic Cramer's V coefficient. The chi ${ }^{2}$ test is a popular non-parametric statistic for testing hypotheses when all variables are nominal [46]. The calculated statistic $\chi^{2}$ reflects the difference between the observed counts and the counts expected if there was no relationship between the analysed variables. Cramer's V is a standardized strength test for $\mathrm{chi}^{2}$, calculated according to the Formula (5).

$$
V=\sqrt{\frac{\chi^{2}}{n(k-1)}}
$$

where: $n$ is a total number of observations and $k$ is a number of columns or rows (whichever is less) of the table with an actual count of the cases.

Cramer's V coefficient was used to assess the strength of the relationship between a chosen transport mode and respondent's characteristics (i.e., gender, age group, function, car availability). The statistic gives a value between 0 and 1 . The higher the value, the stronger the relationship between variables.

Taking into account the results of $\mathrm{chi}^{2}$ independence test, the academic community was divided into segments of similar patterns and transport choice determinants. For this purpose, the classification trees method and the CHAID ( $\mathrm{Chi}^{2}$ Automatic Interaction Detector) algorithm were used. The calculations were performed using statistical software [47].

\subsection{Traffic Counts and Trip Generation Estimation}

In addition to the survey, car traffic, walking and cycling in both campuses were measured at the gates. GUT's car traffic data were extracted from the university's automatic access control system for a full week. In addition, car, pedestrian and cycle traffic was measured on a typical school day from $7 \mathrm{am}$ to $8 \mathrm{pm}$ at the main gate and in peak hours ( $7 \mathrm{am}-9 \mathrm{am}, 2 \mathrm{pm}-5 \mathrm{pm})$ at the other campus gates in both directions (moving to and from university). In the case of car traffic measured at the gates, the number of people in cars was registered, which helped to determine mean car occupancy. UG's measurements 
were not as extensive and looked at a selected representative weekday and the car, pedestrian and cycle traffic entering and exiting the university during the morning peak hour. The daily traffic generation for GUT was estimated based on the daily traffic distribution at the campuses' gates. The objective of the count was to identify the total number of trips which the universities absorbed and generated during the analyzed period. The survey results were then used to calculate the trips by different transport modes. Using the estimated number of trips, trip generation rates were calculated. Trip generation rate is the average number of trips for a given facility per unit of independent variable (i.e., number of employees, dwelling units, area), that can be used i.e., for travel demand forecasting [48]. For the analyzed universities trip generation rates were calculated as a daily number of trips (a sum of trips to and from university) per 1000 university students.

\section{Results}

\subsection{Modal Split}

The work confirmed the assumptions and previous results [21,29] of how students and staff commute to the university (Table 4). Most staff commute by car (57\%). Only $28 \%$ of staff use public transport, a mode predominantly used by students (57\%). More students $(15 \%)$ than staff $(5 \%)$ walk to the university. This has to do with the distance between university and home. Many students live very close to the university in the dormitories (51\% of those walking to university) or in rented flats ( $40 \%$ of those walking to university). A good walking distance is one of the criteria for choosing a place to live. According to the literature, the acceptable walking distance can vary by purposes and groups from 0.4 to 1 kilometre [49]. Flats within walking distance offer savings in terms of time and money. Distance and time are the most important factors for both cases while the use of public transport instead of walking increases the importance of economy and safety [50]. When they decide on a transport mode, students tend to focus on the mode's economy much more than staff (Table 7).

University teachers are the biggest group of university staff. Their transport patterns differ depending on the function they hold (Table 5). Professors, senior lecturers or docents tend to use the car to commute more than research assistants, assistant professors or lecturers. This may have to do with age (usually the higher the position, the older the respondent is), work patterns or adjusting to the perceived social stereotypes.

A comparison of the modal split of both university communities shows similarities in commutes by bicycle and car (Table 4). The differences can be seen in public transport trips and walking. Walking represents a higher proportion at GUT, possibly a result of dormitories situated within walking distance from the campus and a higher proportion of students living in dormitories ( $14 \%$ of students). Only half of UG's dormitories are within walking distance to the campus with $6 \%$ of students living there. Students who prioritized rent affordability tend to live close to public transport stops and are more likely to use transit [51]. Students living in the family home represent a higher percentage at UG (52\%) than at GUT $(43 \%)$.

Table 4. Modal split for UG and GUT by students and staff.

\begin{tabular}{|c|c|c|c|c|c|}
\hline University & Status & Car & Public Transport & Cycling & Walking \\
\hline \multirow{3}{*}{ UG } & Employees & $55 \%$ & $29 \%$ & $12 \%$ & $4 \%$ \\
\hline & Students & $24 \%$ & $64 \%$ & $5 \%$ & $7 \%$ \\
\hline & All & $27 \%$ & $61 \%$ & $5 \%$ & $7 \%$ \\
\hline \multirow{3}{*}{ GUT } & Employees & $61 \%$ & $27 \%$ & $7 \%$ & $5 \%$ \\
\hline & Students & $18 \%$ & $51 \%$ & $6 \%$ & $25 \%$ \\
\hline & All & $22 \%$ & $49 \%$ & $6 \%$ & $23 \%$ \\
\hline \multicolumn{2}{|c|}{ Employees } & $57 \%$ & $28 \%$ & $10 \%$ & $5 \%$ \\
\hline \multicolumn{2}{|c|}{ Students } & $21 \%$ & $59 \%$ & $5 \%$ & $15 \%$ \\
\hline
\end{tabular}


Table 5. Modal split by function.

\begin{tabular}{lcccc}
\hline \multicolumn{1}{c}{ Function } & Car & Public Transport & Cycling & Walking \\
\hline administration & $58 \%$ & $32 \%$ & $6 \%$ & $4 \%$ \\
academic teacher & $58 \%$ & $28 \%$ & $9 \%$ & $5 \%$ \\
assistant professor & $53 \%$ & $32 \%$ & $11 \%$ & $4 \%$ \\
research assistant & $46 \%$ & $35 \%$ & $9 \%$ & $10 \%$ \\
docent & $88 \%$ & $6 \%$ & $6 \%$ & $0 \%$ \\
lecturer/instructor & $59 \%$ & $35 \%$ & $7 \%$ & $0 \%$ \\
professor & $63 \%$ & $24 \%$ & $9 \%$ & $3 \%$ \\
senior lecturer & $81 \%$ & $10 \%$ & $4 \%$ & $5 \%$ \\
lecturer & $54 \%$ & $28 \%$ & $12 \%$ & $7 \%$ \\
librarian & $38 \%$ & $43 \%$ & $12 \%$ & $7 \%$ \\
technician & $53 \%$ & $32 \%$ & $10 \%$ & $5 \%$ \\
service & $64 \%$ & $19 \%$ & $13 \%$ & $5 \%$ \\
student & $15 \%$ & $66 \%$ & $6 \%$ & $13 \%$ \\
student in absentia & $51 \%$ & $44 \%$ & $3 \%$ & $1 \%$ \\
PhD student & $26 \%$ & $35 \%$ & $12 \%$ & $28 \%$ \\
\hline
\end{tabular}

\subsection{Determinants of Transport Mode Choices}

The observed differences in transport patterns depending on the status, function or position prompted the authors to analyse the problem and establish whether there is a significant relation between the selected transport mode and respondent characteristics. Another objective was to identify the strongest factors. $\mathrm{Chi}^{2}$ tests were carried out and Cramer's V coefficient was used that helps to measure the strength of the relation between the variables. The results presented in Table 6 show that the strongest determinant when selecting a transport mode is car availability, followed by respondent status (student/staff) and trip origin location. In the case of students, the type of residence (home, hostel, shared apartment) was also found to have an effect. Other determinants such as gender or age group were found to have a significant yet a much smaller effect. However, a comparison of modal split for men and women or different age groups shows some differences. As an example, to commute women choose the car $(29.9 \%$ vs. $35.6 \%)$ or bicycle $(5.4 \%$ vs. $8.6 \%)$ less often than men and choose public transport more often than men $(53.7 \%$ vs. $43.6 \%)$. Looking at the employees and their age group (Figure 3) it can be observed that young employees ( $<35$ years) are more likely to choose non-motorised transport modes than older employees ( $>65$ years old).

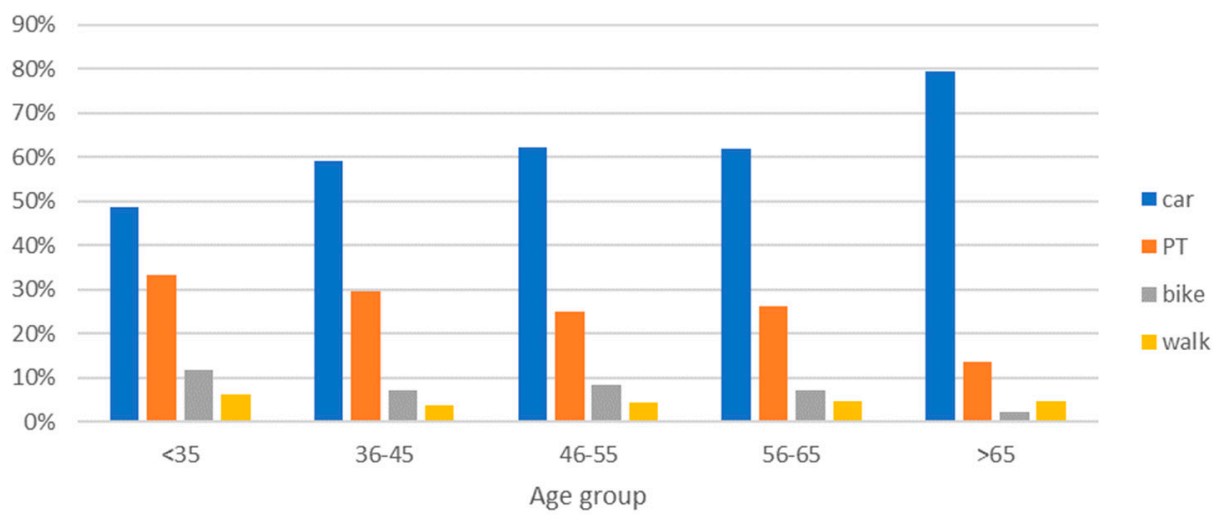

Figure 3. The relation between age group and modal split. 
Table 6. Results of $\mathrm{chi}^{2}$ independence analysis-relation between modal split and respondent characteristics variables.

\begin{tabular}{ccccc}
\hline Variable & Analysed Group & $\boldsymbol{p}$ Value & $\boldsymbol{\chi}^{\mathbf{2}}$ & Cramer's V \\
\hline University & all & $<0.05$ & 44.1 & 0.11 \\
Gender & all & $<0.05$ & 38.7 & 0.11 \\
Status & all & $<0.05$ & 610.5 & 0.43 \\
Age group & all & $<0.05$ & 499.6 & 0.22 \\
Age group & employees & $<0.05$ & 27.4 & 0.09 \\
Unit & all & $<0.05$ & 317.8 & 0.18 \\
Function & all & $<0.05$ & 775.8 & 0.28 \\
Function & students & $<0.05$ & 185.1 & 0.17 \\
Function & employees & $<0.05$ & 14.2 & 0.06 \\
Position & academic teachers & $<0.05$ & 31.5 & 0.13 \\
Additional duties/work & students & $<0.05$ & 116.7 & 0.17 \\
Type of residence & students & $<0.05$ & 712.7 & 0.33 \\
Car availability & all & $<0.05$ & 1160.1 & 0.59 \\
Car availability & employees & $<0.05$ & 334.8 & 0.53 \\
Car availability & students & $<0.05$ & 603.8 & 0.53 \\
City & all & $<0.05$ & 579.6 & 0.24 \\
District & Gdansk residents & $<0.05$ & 913.4 & 0.37 \\
Frequency of travel (days) & all & $<0.05$ & 103.3 & 0.10 \\
\hline
\end{tabular}

Table 6 suggests that there is a relation between the modal choice and district as the trip origin location. Its transport accessibility was checked (Formula (2)) for its effect on the transport choices of students/staff. It was observed that the higher the district's public transport accessibility, the lower the share of trips by car (Figure 4). This means that more accessible districts give more and better possibilities for non-motorised trips.

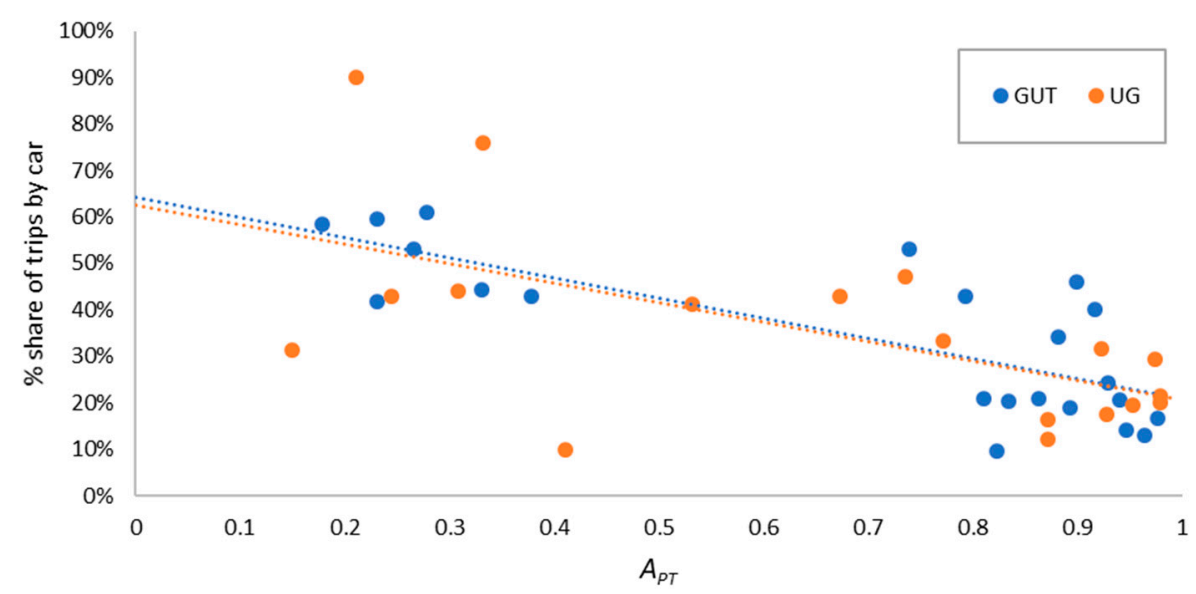

Figure 4. The relation between district accessibility and share of car trips from that district.

As we know from the analyses, students who rent flats are more likely to choose accessible districts-more than $90 \%$ of those students rent a room/flat in a district whose PT accessibility is $>0.7$ and $64 \%$ choose districts with the highest PT accessibility of $>0.9$.

\subsection{Transport Mode Selection Criteria}

Considering the criteria followed by respondents in the choice of transport mode, staff and students differed on the ones they picked. Staff appreciated the directness, duration, convenience, and flexibility (ability to run errands on the way) of trips with $40-50 \%$ of staff identifying these criteria. Students, however, much more than staff put travel costs first rather than flexibility (Table 7). Students are twice as likely as staff to choose a transport mode because there are no other options. 
Table 7. Declared criteria of transport mode choice by staff and students.

\begin{tabular}{ccccccccccc}
\hline Criteria & \multicolumn{2}{c}{ All Modes } & \multicolumn{2}{c}{ Car } & \multicolumn{2}{c}{ PT } & \multicolumn{2}{c}{ Cycling } & \multicolumn{2}{c}{ Walking } \\
& E & S & E & S & E & S & E & S & E & S \\
\hline Directness & $47 \%$ & $44 \%$ & $57 \%$ & $72 \%$ & $40 \%$ & $35 \%$ & $20 \%$ & $39 \%$ & $25 \%$ & $46 \%$ \\
Time & $51 \%$ & $37 \%$ & $66 \%$ & $79 \%$ & $28 \%$ & $24 \%$ & $45 \%$ & $67 \%$ & $15 \%$ & $30 \%$ \\
Comfort & $53 \%$ & $29 \%$ & $70 \%$ & $77 \%$ & $27 \%$ & $15 \%$ & $37 \%$ & $39 \%$ & $24 \%$ & $26 \%$ \\
Elasticity & $41 \%$ & $18 \%$ & $62 \%$ & $61 \%$ & $9 \%$ & $5 \%$ & $21 \%$ & $37 \%$ & $15 \%$ & $14 \%$ \\
Costs & $22 \%$ & $36 \%$ & $10 \%$ & $9 \%$ & $41 \%$ & $45 \%$ & $37 \%$ & $37 \%$ & $20 \%$ & $29 \%$ \\
Ecology & $9 \%$ & $9 \%$ & $1 \%$ & $1 \%$ & $17 \%$ & $8 \%$ & $39 \%$ & $23 \%$ & $15 \%$ & $14 \%$ \\
Enjoyment & $15 \%$ & $12 \%$ & $10 \%$ & $22 \%$ & $5 \%$ & $2 \%$ & $67 \%$ & $56 \%$ & $36 \%$ & $22 \%$ \\
No other option & $10 \%$ & $24 \%$ & $7 \%$ & $11 \%$ & $20 \%$ & $35 \%$ & $0 \%$ & $1 \%$ & $0 \%$ & $10 \%$ \\
Living nearby & $3 \%$ & $13 \%$ & $0 \%$ & $0 \%$ & $0 \%$ & $0 \%$ & $0 \%$ & $0 \%$ & $69 \%$ & $87 \%$ \\
Activity & $9 \%$ & $9 \%$ & $0 \%$ & $0 \%$ & $0 \%$ & $0 \%$ & $73 \%$ & $59 \%$ & $51 \%$ & $34 \%$ \\
\hline
\end{tabular}

When viewed in the context of respondent transport choices, the selection criteria differ depending on how a respondent travels to and from the university. We can see that car users point to directness, time, comfort and flexibility. While public transport users appreciate directness, they also value the costs. Students will often pick public transport just because there is nothing else to choose. Cyclists make their choice because they enjoy cycling and get some exercise while cycling; students also choose the bicycle for the duration of the trip. Walking is mostly related to living near the university.

\subsection{Classification of Transport Behaviour}

The results of the analyses showed that transport choices largely depend on respondent characteristics. Segmentation helped to identify homogenous groups within the academic community against the factors listed in Table 6. Commonly used in management and marketing, segmentation disaggregates a community into separate schemes and identifies homogenous groups called market segments [21]. The analysis used the method of classification trees. The analysis only looked at people living (permanent/temporary residence) in Gdansk to take account of district accessibility, which was proved to have an effect on transport choices. The tree is presented in Figure 5.

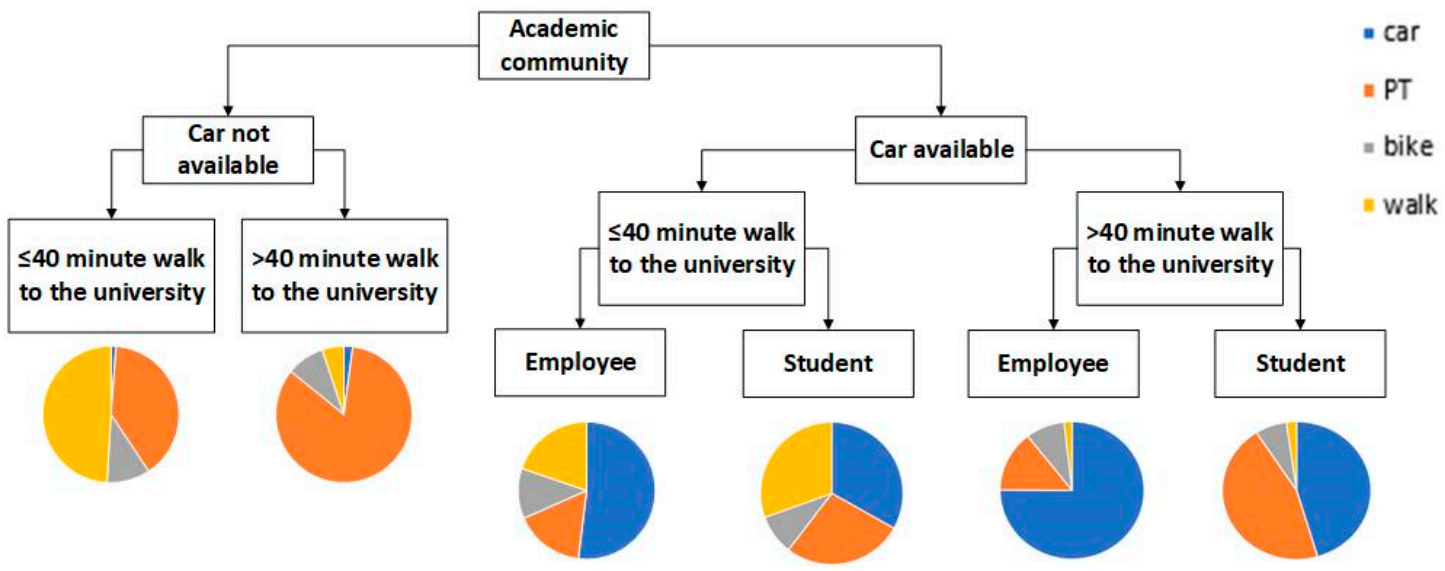

Figure 5. Academic community classification by transport behaviour.

The most significant variable producing the first division is car availability, a factor that most strongly differentiates between the groups' modal splits. With no access to a car, a person will choose other modes of transport, unless they are a car passenger. The kind of transport mode a person chooses depends on the district's location, i.e., the origin of the trip. For locations within walking distance (up to $40 \mathrm{~min}$-value corresponding to $A_{W} \geq 0.83$ resulting from the analysis), it is highly likely that the person will choose to walk. For longer distances, PT will be the main transport mode. Those with access to a car will use it more often to travel. The extent of that depends on the location of the district (criterion of walking distance) and the group they belong to (staff/student). 
The analyses helped to identify six homogenous segments of transport behaviour:

- Group 1-no car availability, living within walking distance from the university (mostly walking and frequently using public transport)—modal split: 1\% car, 39\% PT, 10\% bike, 49\% walk;

- group 2-no car availability, living further away from the university (public transport used most often)-modal split: $2 \%$ car, $84 \%$ PT, $9 \%$ bike, $5 \%$ walk;

- group 3-car availability, living within walking distance from the university, member of staff (half of the trips by car, many by foot or cycling)—modal split: $52 \%$ car, $16 \%$ PT, $12 \%$ car, $20 \%$ walk;

- group 4-car availability, living within walking distance from the university, student (1/3 of trips by foot, $1 / 3$ by car, the rest walking or cycling) — modal split: 33\% car, 27\% PT, 9\% bike, 30\% walk;

- group 5-car availability, living further away from the university, member of staff (car dominance)—modal split: $75 \%$ car, $14 \%$ PT, $9 \%$ bike, $2 \%$ walk;

- group 6-car availability, living further away from the university, student (nearly half of the trips by car, the rest mostly by PT) — modal split: $45 \%$ car, $45 \%$ PT, 7\% bike, $2 \%$ walk.

Understanding the structure of academic community helps to identify the potential and ability to change people's transport behaviour and patterns. The results of the study can translate into specific measures designed to change the mentality and transport behaviour or to maintain the observed sustainable transport patterns. A lot will depend, however, on how willing the particular segments are to change their transport behaviour.

\subsection{Potential for Changing Transport Behaviour}

The questionnaire asked staff and students who commute to university by car whether they are willing to reduce car use in everyday trips to and from university and under what conditions. The results show that half of the staff and $60 \%$ of students who choose the car for trips do not feel the need to change their transport behaviour. About $1 / 3$ in both groups would like to change but cannot ( $70 \%$ of these people said they had no other option as a criterion of transport mode choice). $21 \%$ of staff and $12 \%$ of students declare their willingness to change their transport behaviour under specific conditions. These were usually related to incentives and improvements universities should offer to encourage active forms of mobility and better transport services. What this means is that by promoting cycling and walking and a better provision of cycling infrastructure [21,52], car trips could actually be reduced. Based on the declared potential to swap the car for a different mode, the possible reduction in car commuters could be as high as $14 \%$.

In terms of the potential for change of the specific groups of the academic community, the likelihood of changing car users' transport behaviour differs from group to group. Propensity is highest for staff who live within walking distance ( $\leq 40 \mathrm{~min}$.) from the university (group 3 ). In this group, nearly every third employee is willing to change their transport behaviour into a more sustainable one. Staff who live further away from university (group 5 ) are less likely to change with only $18 \%$ declaring willingness. Students are most likely to change $(22 \%)$ if they live further away from university (group 6). There is a surprisingly lower propensity (13\%) of students who live within walking distance from university (group 4) (Table 8).

Table 8. The propensity to change car user transport behaviour by segment.

\begin{tabular}{cccc}
\hline \multirow{2}{*}{ Car Users Group * } & \multicolumn{3}{c}{ Willingness to Change Transport Behaviour } \\
\cline { 2 - 4 } & Propensity & No Possibility & No Need \\
\hline 3 & $28 \%$ & $23 \%$ & $49 \%$ \\
4 & $13 \%$ & $22 \%$ & $64 \%$ \\
5 & $18 \%$ & $27 \%$ & $55 \%$ \\
6 & $22 \%$ & $15 \%$ & $63 \%$ \\
\hline
\end{tabular}

* The car users groups are defined in Section 4.4. 
Understanding the potential for change and the homogenous makeup of transport behaviour segments is likely to improve the effectiveness of mobility management efforts by matching the measures to the groups.

\subsection{Trip Generation}

Given the size of the academic community as part of the city's overall population, it is clear that universities generate a significant number of trips many of which coincide with rush hour. Table 9 shows the results of traffic counts for cars, pedestrians, and cyclists going through campus gates within one hour of the morning peak ( $7 \mathrm{am}-8 \mathrm{am}$ ) and one hour of the afternoon peak ( $2 \mathrm{pm}-3 \mathrm{pm})$, during the typical school day. The traffic was recorded in both directions (entering and exiting university campus). Using traffic counts at GUT it is estimated that the morning peak hour includes $16 \%$ of daily inbound trips and $4 \%$ of outbound trips with $8 \%$ and $12 \%$ in the afternoon peak hour, respectively. During morning rush hour $80 \%$ of the trips are into the campus and $20 \%$ out of the campus. During the afternoon rush hour, the shares are $40 \%$ and $60 \%$, respectively.

Table 9. Number of cars and people recorded at university gates during morning and afternoon peak hours and the estimated total number of trips to and from the university.

\begin{tabular}{cccccc}
\hline & Cars & Car Occupants * & Pedestrians & Cycles & Total Number of Trips (People) \\
\hline GUT morning & 259 & 383 & 2833 & 57 & 3274 \\
GUT afternoon & 196 & 290 & 3065 & 81 & 3436 \\
UG morning & 778 & 1105 & 2188 & 32 & 3325 \\
UG afternoon ** & 603 & 856 & 2471 & 47 & 3374 \\
\hline
\end{tabular}

${ }^{*}$ mean occupancy: 1.42 UG and 1.48 GUT, ${ }^{* *}$ estimated based on hourly distribution at GUT.

As we can see from Table 9, for an analogous number of trips GUT records more pedestrians than UG and significantly fewer car trips. More people walk because there are more dormitories (about 2600 places) within walking distance from the GUT campus. In the case of car trips, UG's higher number may be down to a better provision of parking (at UG most drivers park on university premises while parking at GUT is only available to staff). This is confirmed by survey results. In the case of GUT, nearly $100 \%$ of staff and $0 \%$ of students park on the campus. In the case of UG nearly $100 \%$ of respondents (students and staff) park on the campus.

The GUT survey helped to estimate the daily number of generated trips at 34,000 trips. When related to the number of the university's students, there are about 1400 trips daily per 1000 students. Considering the survey's modal split, per 1000 students there are about 330 car trips (which corresponds to 230 vehicles), 810 public transport trips, 30 cycle trips and 240 trips by foot. Because UG has similar characteristics, the same rates can be applied. As a result, it was estimated that the main UG campus generates daily more than 30,000 trips. With numbers like these, the traffic contribution from both universities is significant for the city as a whole and clearly for the immediate neighbourhood. Taking into account the average daily number of trips in Gdansk (Section 3.1) it can be estimated that GUT and UG's main campus are responsible for about $7 \%$ of urban traffic. The results can be used to identify how strong the impact of universities is on the adjacent streets and to understand the potential of modal split changes on the number of car trips. For example, if the results from point 4.5 were taken into account, it can be estimated, that if we convince the $14 \%$ of drivers that are willing to change their behaviour to change their transport mode, the number of car trips can decrease by even 50 per 1000 students.

\section{Discussion}

The work helped to identify the transport behaviour of academic communities of two of Gdansk's biggest universities which share similar characteristics, location, and accessibility. With the academic community's average modal split at $25 \%$ car, $55 \%$ PT, $6 \%$ cycling, and $14 \%$ walking, car use for university commutes seems to be more sustainable compared to other surveys $[18,26,29,37]$ reporting 
higher rates (above 40\%). Given the differences in the area of culture, land use, level of socio-economic development, size and location of campuses, the results are hardly comparable. The trendsetters include McGill University in Canada [42] with a dominant role of transit and shuttles (55\%) and very little car traffic $(16 \%)$ or University of Idaho [53] where walking is the most prevalent mode, followed by car and cycling. Considering the potential for change as explained in Section 4.5 , the universities in question stand a good chance of changing their modal split.

The study has confirmed the assumptions and results of previous work [21,29,31] in terms of how students and staff commute. The groups differ on the factors that influence their transport choices (e.g., owning a car, place of residence) and the criteria they follow when choosing a mode (such as convenience or cost of travel). Having access to a car is a key factor behind transport choices. Just as in the work of Vale et al. [29] car availability is higher for staff than for students. This translates into more sustainable transport choices of students compared to staff and other population segments [31,54]. A key driver of choice is the location of the origin of the trip and its links by public transport and walking. The effect of the built environment factor on transport choices is considered in the literature with reference to the trip's origin or destination [55]. The article proposes that a mutual origin and destination relation should be considered expressed as two-way accessibility by PT and walking.

As expected, because both universities share similar characteristics, there were only slight differences in their modal splits. This has to do primarily with a different provision of dormitories. Analogue results of both universities suggest the existence of some general relations that influence the transport choices of students and staff. One of the observations is that specific transport modes are chosen depending on the place of residence and its transport accessibility. The better the transport links, the more likely the choice of a mode other than the car. The actual decision to use the car or a different mode also depends on the preferences (the selection criteria) and the willingness to use sustainable forms to travel to and from the university. As a result, the choice of mode is determined by its accessibility and how well it meets the user's expectations (such as quality or costs of travel), but also their understanding of the need for sustainable mobility. The results of the segmentation further confirmed the above relations which is that the choice of transport mode will largely depend on car availability and where people live and work/study and their status (student/staff).

While universities differ in size, campus organisation, land use and internal and external transport policy, their pressure on the neighbourhood and environment can usually be attributed to the popularity of the car for commuting trips to and from university. Even though car use by the academic communities in question is relatively low as part of their modal split, university generated trips (1400 trips per 1000 students) may affect the district and the city. Despite that, car users' willingness to change transport behaviour as declared in the surveys suggests that the negative impacts of the universities on the environment may be reduced if supported by better quality and accessibility of public transport and university incentives.

\section{Conclusions}

The study helped to understand the current transport behaviour of academic communities of two of Gdansk's universities and the main factors behind this. The lack of homogeneity of the academic community (staff vs. students) was confirmed and groups of homogenous transport behaviour were identified.

The relations established can be used by the analysed universities to:

- Forecast how university generated trips will change in the years to come based on the size of the academic community,

- forecast the modal split for the years to come using the segments already defined based on traveller information such as car ownership, place of residence and status (staff/student),

- estimate the effect of the university on its environment and the city's transport system using the trip generation rates,

- define the capacity for more work to change the modal split, 
- forecast traffic volumes if the university should grow or change its parking provision, and

- develop and adequately address strategies aimed at modal split change and assess how these will influence the impact university has on city's transport system.

Other European universities can also benefit from the results of the work presented in the paper:

- They can apply the proposed methodology (survey design, data preparation and analysis, accessibility indicators, segmentation concept) in order to study transport behaviour of their academic communities.

- If they share similar characteristics to the study sites (urban location, compact university campuses and very good links to public transport), they can apply some of the results, i.e., trip generation rates or segmentation in order to estimate the effect they have on transport system or to divide their community into homogeneous groups.

Knowledge from the study shows that within their remit universities could change the academic community's transport behaviour:

- By providing dormitories in direct proximity to the university, deciding on the university's location and having a consolidation strategy, and

- by taking steps to tap into the academic community's declared willingness to change for a more sustainable transport and actively managing mobility that will work for each of the segments.

Taking into account the scope of the study, further work should focus on assessing the effect of improvements introduced by the city or university to make sustainable transport more attractive for university commuting trips and how they fit into the idea of sustainable university. This will be part of further research.

Author Contributions: Investigation, A.R. and R.O.; Methodology, A.R. and R.O.; Software, A.R.; Supervision, K.J.; Visualization, A.R.; Writing-original draft, A.R., R.O. and K.J.

Funding: This research received no external funding.

Conflicts of Interest: The authors declare no conflict of interest.

\section{References}

1. Tolley, R. Green campuses: Cutting the environmental cost of commuting. J. Transp. Geogr. 1996, 4, 213-217. [CrossRef]

2. Banister, D.; Anderton, K.; Bonilla, D.; Givoni, M.; Schwanen, T. Transportation and the Environment. Annu. Rev. Environ. Resour. 2011, 36, 247-270. [CrossRef]

3. Kenyon, S.; Lyons, G.; Rafferty, J. Transport and social exclusion: Investigating the possibility of promoting inclusion through virtual mobility. J. Transp. Geogr. 2002, 10, 207-219. [CrossRef]

4. Lerner, W. The Future of Urban Mobility: Towards Networked, Multimodal Cities of 2050; Arthur D. Little: Boston, MA, USA, 2011.

5. Commission of the European Communities Green Paper. Towards a New Culture for Urban Mobility; Commission of the European Communities: Brussels, Belgium, 2007.

6. Commission of the European Communities. White Paper on Transport. Roadmap to a Single European Transport Area-towards a Competitive and Resource Efficient Transport System; Commission of the European Communities: Brussels, Belgium, 2011.

7. Okraszewska, R.; Romanowska, A.; Wołek, M.; Oskarbski, J.; Birr, K.; Jamroz, K. Integration of a multilevel transport system model into sustainable Urban mobility planning. Sustainability 2018, 10, 479. [CrossRef]

8. Deutscher, I. What We Say/What We Do: Sentiment and Acts; Scott, Foresman: Glenview, IL, USA, 1973.

9. Van Weenen, H. Towards a vision of a sustainable university. Int. J. Sustain. High. Educ. 2000, 1, 20-34. [CrossRef]

10. Association of University Leaders for a Sustainable Future. The Talloires Declaration 10 Point Action Plan; Association of School and College Leaders: Leicester, UK, 1999. 
11. Hancock, L.; Nuttman, S. Engaging higher education institutions in the challenge of sustainability: Sustainable transport as a catalyst for action. J. Clean. Prod. 2014, 62, 62-71. [CrossRef]

12. Joseph, C.; Engkamat, A.; Tawie, R. Sustainability Disclosure on Malaysian University Websites. In Proceedings of the 25th Asian-Pacific Conference on International accounting issues, Bali, Indonesia, 10-13 November 2013.

13. Kaplan, D.H. Transportation sustainability on a university campus. Int. J. Sustain. High. Educ. 2015, 16, 173-186. [CrossRef]

14. Okraszewska, R.; Romanowska, A.; Jamroz, K. The Effect of University Campuses on the Modal Split of Polish Cities. In Proceedings of the Intelligent Transport Systems and Travel Behaviour 13th Scientific and Technical Conference "Transport Systems. Theory and Practice 2016", Katowice, Poland, 19-21 September 2016; Selected Papers. Springer International Publishing: Berlin, Germany, 2017; pp. 65-74.

15. Rotaris, L.; Danielis, R. Commuting to college: The effectiveness and social efficiency of transportation demand management policies. Transp. Policy 2015, 44, 158-168. [CrossRef]

16. Rotaris, L.; Danielis, R. The impact of transportation demand management policies on commuting to college facilities: A case study at the University of Trieste, Italy. Transp. Res. Part A Policy Pract. 2014, 67, 127-140. [CrossRef]

17. Vanasse Hangen Brustlin Inc. Campus Transportation Plan University of Massachusetts Lowell; Vanasse Hangen Brustlin Inc.: Watertown, MA, USA, 2011.

18. Romanowska, A.; Okraszewska, R.; Jamroz, K. Universities as Part of the Urban Transport System-Analysis Using the Example of the Gdansk University of Technology and Medical University of Gdansk. In Sustainable Transport Development, Innovation and Technology; Suchanek, M., Ed.; Springer: Berlin, Germany, 2017; pp. 119-128.

19. Norton, R.K.; Brix, A.; Brydon, T.; Davidian, E.; Dinse, K.; Vidyarthi, S. Transforming the University Campus into a Sustainable Community. Plan. High. Educ. 2007, 35, 22-39.

20. Toor, W.; Spenser, W. Transportation and Sustainable Campus Communities: Issues, Examples, Solutions. Int. J. Sustain. High. Educ. 2004, 13, 203-204.

21. Okraszewska, R.; Romanowska, A.; Jamroz, K. Segmentation of academic community for the purposes of mobility plan development-case study of Gdansk University of Technology. ICERI Proc. 2016, 4221-4231. [CrossRef]

22. Cooper, A.; Johnson, I.; Michaan, K.; Berg, Z.; Dessauer, L.; Fuentes, J.; Labadie, K.; Zhou, Y.; Koh, Y.M.; Rossi, A.; et al. A Sustainable Campus for the Future: Proposals for Sarah Lawrence College. Campus Environmental Sustainability Project. Book 10; Sarah Lawrence University: Bronxville, NY, USA, 2016.

23. Šmid, P.; Lukešová, D.; Mourek, P. Mobility Plans; Fundacja Partnerstwo dla Środowiska: Cracow, Poland, 2011; ISBN 9788361733102.

24. Zhou, J. Sustainable commute in a car-dominant city: Factors affecting alternative mode choices among university students. Transp. Res. Part A Policy Pract. 2012, 46, 1013-1029. [CrossRef]

25. Gatersleben, B.; Uzzell, D. Affective Appraisals of the Daily Commute. Environ. Behav. 2007, 39, 416-431. [CrossRef]

26. Shannon, T.; Giles-Corti, B.; Pikora, T.; Bulsara, M.; Shilton, T.; Bull, F. Active commuting in a university setting: Assessing commuting habits and potential for modal change. Transp. Policy 2006, 13, 240-253. [CrossRef]

27. Petrik, O.; Silva, J.; Moura, F. Stated preference surveys in transport demand modeling: Disengagement of respondents. Transp. Lett. 2016, 8, 13-25. [CrossRef]

28. Ministry of Works and Transport Roads Department. Traffic Data Collection and Analysis; Hastings District Council: Hasting, New Zealand, 2004; ISBN 99912-0-417-2.

29. Vale, D.S.; Pereira, M.; Viana, C.M. Different destination, different commuting pattern? Analyzing the influence of the campus location on commuting. J. Transp. Land Use 2018, 11, 1-18. [CrossRef]

30. Rainham, D.G.; Bates, C.J.; Blanchard, C.M.; Dummer, T.J.; Kirk, S.F.; Shearer, C.L. Spatial Classification of Youth Physical Activity Patterns. Am. J. Prev. Med. 2012, 42, e87-e96. [CrossRef]

31. Whalen, K.E.; Páez, A.; Carrasco, J.A. Mode choice of university students commuting to school and the role of active travel. J. Transp. Geogr. 2013, 31, 132-142. [CrossRef]

32. Domarchi, C.; Tudela, A.; González, A. Effect of attitudes, habit and affective appraisal on mode choice: An application to university workers. Transportation 2008, 35, 585-599. [CrossRef] 
33. Wuerzer, T.; Mason, S.G. Cycling willingness: Investigating distance as a dependent variable in cycling behavior among college students. Appl. Geogr. 2015, 60, 95-106. [CrossRef]

34. Chowdhury, S.; Ceder, A.; Schwalger, B. The effects of travel time and cost savings on commuters' decision to travel on public transport routes involving transfers. J. Transp. Geogr. 2015, 43, 151-159. [CrossRef]

35. Badland, H.; Hickey, S.; Bull, F.; Giles-Corti, B. Public transport access and availability in the RESIDE study: Is it taking us where we want to go? J. Transp. Heal. 2014, 1, 45-49. [CrossRef]

36. Balsas, C.J. Sustainable transportation planning on college campuses. Transp. Policy 2003, 10, 35-49. [CrossRef]

37. Miralles-Guasch, C.; Domene, E. Sustainable transport challenges in a suburban university: The case of the Autonomous University of Barcelona. Transp. Policy 2010, 17, 454-463. [CrossRef]

38. Kuzia, M.; Przybyłowski, A. Challenges for Urban Sustainable Mobility - Gdynia Maritime University Case Study. Econ. Environ. Stud. 2017, 17, 1071-1085. [CrossRef]

39. Nguyen-Phuoc, D.Q.; Amoh-Gyimah, R.; Tran, A.T.P.; Phan, C.T. Mode choice among university students to school in Danang, Vietnam. Travel Behav. Soc. 2018, 13, 1-10. [CrossRef]

40. Soltani, A.; Allan, A.; Nguyen, H.A.; Berry, S. Students' commuting pattern from the viewpoint of environmentalism: Comparing Australia with China. Int. J. Sustain. High. Educ. 2019, 20, 91-114. [CrossRef]

41. Das, R.; Vishal Kumar, S.; Prakash, B.; Dharmik; Subbarao, S.S.V. Analysis of University Students Travel Behaviour: En Route to Sustainable Campus. Indian J. Sci. Technol. 2016, 9. [CrossRef]

42. Jacques, C.; Chakour, V.; Mathez, A.; Manaugh, K.; Barreau, G.; Hatzopoulou, M.; Eluru, N.; El-Geneidy, A. An Examination of Commuting Patterns to McGill University. Results of the 2011 McGill Transportation Survey. Final Report; McGill University: Montreal, QC, Canada, 2011.

43. VIA VISTULA. Gdansk Traffic Research. A Leaflet; VIA VISTULA: Gdańsk, Poland, 2016. (In Polish)

44. Smith, M.E. Design of small sample home-interview travel surveys. Transp. Res. Rec. 1979, 701, $29-35$.

45. Sharot, T. Weighting survey results. J. Mark. Res. Soc. 1986, 28, 269-284.

46. McHugh, M.L. The chi-square test of independence. Biochem. Med. 2013, 23, 143-149. [CrossRef]

47. Dell Inc. Dell Statistica (Data Analysis Software System), Version 13; Dell Inc.: Round Rock, TX, USA, 2016.

48. Institute of Transportation Engineers. Trip Generation, 8th ed.; ITE: Washington, DC, USA, 2008.

49. Yang, Y.; Diez-Roux, A.V. Walking distance by trip purpose and population subgroups. Am. J. Prev. Med. 2012, 43, 11-19. [CrossRef] [PubMed]

50. Kotoula, K.M.; Sialdas, A.; Botzoris, G.; Chaniotakis, E.; Salanova Grau, J.M. Exploring the Effects of University Campus Decentralization to Students' Mode Choice. Period. Polytech. Transp. Eng. 2018, 46, 207-214. [CrossRef]

51. Zhou, J.; Wang, Y.; Wu, J. Mode Choice of Commuter Students in a College Town: An Exploratory Study from the United States. Sustainability 2018, 10, 3316. [CrossRef]

52. Okraszewska, R. Impact of Cyclist Facility Availability at Work on the Number of Bike Commuters; Springer: Berlin, Germany, 2019; pp. 95-105.

53. Delmelle, E.M.; Delmelle, E.C. Exploring spatio-temporal commuting patterns in a university environment. Transp. Policy 2012, 21, 1-9. [CrossRef]

54. Santos, G.; Maoh, H.; Potoglou, D.; von Brunn, T. Factors influencing modal split of commuting journeys in medium-size European cities. J. Transp. Geogr. 2013, 30, 127-137. [CrossRef]

55. Wesselink, R.; Studynka, O.; Kemp, R.; Kemp, R. Encouraging sustainability in the workplace: A survey on the pro-environmental behaviour of university employees. J. Clean. Prod. 2015, 106, 55-67.

(C) 2019 by the authors. Licensee MDPI, Basel, Switzerland. This article is an open access article distributed under the terms and conditions of the Creative Commons Attribution (CC BY) license (http://creativecommons.org/licenses/by/4.0/). 